\title{
Infinite Value and the Best of All Possible Worlds ${ }^{1}$
}

\author{
NEVIN CLIMENHAGA \\ University of Notre Dame
}

\begin{abstract}
A common argument for atheism runs as follows: God would not create a world worse than other worlds he could have created instead. However, if God exists, he could have created a better world than this one. Therefore, God does not exist. In this paper I challenge the second premise of this argument. I argue that if God exists, our world will continue without end, with God continuing to create value-bearers, and sustaining and perfecting the value-bearers he has already created. Given this, if God exists, our world — considered on the whole - is infinitely valuable. I further contend that this theistic picture makes our world's value unsurpassable. In support of this contention, I consider proposals for how infinitely valuable worlds might be improved upon, focusing on two main ways - adding value-bearers and increasing the value in present value-bearers. I argue that neither of these can improve our world. Depending on how each method is understood, either it would not improve our world, or our world is unsurpassable with respect to it. I conclude by considering the implications of my argument for the problem of evil more generally conceived.
\end{abstract}

One atheistic argument from evil proceeds as follows:

(1) If God exists, he would only create a world if there is no better world that he could have created instead.

(2) If God exists, he could have created a better world than this one.

Since, if God exists, he created this world, the consequents of (1) and (2) cannot both be true. It follows that their antecedent is false, and that

(3) God does not exist.

Call this argument the Argument from Surpassability, or AFS for short. ${ }^{2}$ Leibniz (1710) famously denied (2) of this argument, claiming that ours is the unique best of all possible

This paper was written with the support of a generous grant from the Templeton Foundation on Contemporary Moral Theory and the Problem of Evil (grant number 43655). I am grateful to Jim Sterba, the leader of that project, and my fellow research assistant Meg Schmitt for their helpful discussion and comments on early drafts of this paper. I would also like to thank participants in the Center for Philosophy of Religion Discussion Group at Notre Dame for their feedback on a draft of this paper, and Dustin Crummett in particular for his extensive written comments and extremely helpful discussion of the issues explored in this paper.

2 The AFS is expressed in basically this form by Perkins (1983), Sobel (2004: 468), Wielenberg (2004: 57), Hudson (2013: 236), and Kraay (2013: 399). Some presentations of the argument replace (1) above with the claim that God must create the best possible world. However, this presupposes that there is a single best possible world. (1) leaves open the possibility that there are multiple equally good or incomparable worlds such that no world is better than any of these worlds. Another variation on this argument replaces (2) with the stronger claim that for any possible world, there is a better one creatable by God. Since the second premise of this argument is logically stronger than (2), my argument against (2) in this paper also challenges this argument. 
worlds. Contemporary theistic philosophers have generally been reticent to follow him in this. Robert Adams (1972) denies (1) by arguing that by failing to create a better world than he did God would not necessarily be violating anyone's rights or manifesting a defect in character, and could in fact be manifesting grace. ${ }^{3}$ Other theistic philosophers have objected to (1) with the following argument: there is no best possible world; for $\mathrm{ev}$ ery world that God can create, there is a better one that he could have created instead. ${ }^{4}$ Thus, it is unreasonable to blame God for not creating a better world, because it is logically impossible for him to both create a world and satisfy the consequent of (1). Skeptics of this move have responded that if (1) is false, this implies that a perfect being (like God) is impossible - for a perfect being would never perform a surpassable action, and yet the fact that there is no best possible world makes it impossible for a creator to avoid performing a surpassable action. ${ }^{5}$

In this paper I follow Leibniz in arguing against (2). Unlike Leibniz, however, I do not think that our world is the uniquely best world. Instead, I argue for the weaker conclusion that there are not other worlds better than ours. It is compatible with this conclusion that the goodness of some other worlds is equal to or incomparable with that of ours.

My argument proceeds in two stages. First, I argue that given theological assumptions that the proponent of the AFS ought to accept, if God created the world, then there is an infinite amount of value in our world. Second, I argue that, given these assumptions, not only is our world infinitely valuable, it is unsurpassable: on any plausible principles that allow us to rank different infinitely valuable worlds, there are no other infinitely valuable worlds better than this world.

I should stress at the outset that I do not think that my argument solves the "problem of evil" more generally. There remain serious philosophical objections to theism based on the existence of the evil we find in our world even if my argument works. However, I think that my argument does show that the AFS is not the best way to formulate the problem of evil. While God's existence may be incompatible with or disconfirmed by the evils in the world, this is not because those evils make the world as a whole worse than it may have otherwise been. I explore the relation between my argument and the problem of evil more generally in the final section of this paper.

For criticisms of Adams, see Quinn (1992), Grover (2003), Wielenberg (2004), and Rowe (2004: 74-87).

4 See, e.g., Plantinga (1976: 61), Schlesinger (1977: ch. 9-10), Forrest (1981), Reichenbach (1982: 12228), Morris (1993), and Swinburne (1994: 134-36) and (2004: 113-15).

$5 \quad$ See Quinn (1992), Perkins (1983: 247), Grover (1988, 2004), Wielenberg (2004: 56-59), Rowe (2004: 88142), and Kraay (2010). Leibniz explicitly rejected the possibility of an infinitely improving series of worlds, on the grounds that this would make God's choice to create violate the Principle of Sufficient Reason (see Blumenfeld [1975] for discussion). Contemporary defenders of the claim that a God with no best world to create could not be perfect frequently appeal to the possibility of morally or rationally superior "rival creators." This basic idea was suggested in Kant's Lectures on Philosophical Theology (1978: 137):

That the world created by God is the best of all possible worlds, is clear for the following reason. If a better world than the one willed by God were possible, then a will better than the divine will would also have to be possible. For indisputably that will is better which chooses what is better. But if a better will is possible, then so is a being who could express this better will. And therefore this being would be more perfect and better than God. But this is a contradiction; for God is omnitudo realitatis. 


\section{Preliminary Remarks}

In this essay I understand God to be the omnipotent, omniscient, and perfectly good creator of all contingent things. I understand the world to include all of space and time and anything that exists outside of space and time. In other words, 'the world' refers to all of reality (including God). Importantly, on this definition of 'world,' there can be only one actual world. Now, (for all I know) God could create multiple spatiotemporally closed systems; in this case I will say that God creates several universes. So there can be only one world, but many universes. Strictly speaking God creates universes (and the things in them), not worlds, since a world includes God. However, I will sometimes speak loosely of God creating worlds; the reader should understand this to mean God's creating the contingent things in a world, including the universe(s) it contains.

I assume, for simplicity's sake, that God has knowledge of all future events, including (if such there be) indeterministic events or libertarian free actions, and I will ignore possible constraints on what possible worlds God can create arising from indeterministic events or libertarian free actions. I will also speak as if God acts in time; later, I will consider how to reformulate relevant parts of my argument without this assumption.

I further assume that it is possible to rank worlds according to their goodness or value. $^{6}$ (In this paper, I use 'value' and 'goodness' interchangeably.) Although I proceed as if world-values are measurable by some precise number, my arguments could be reformulated with ranges or sets of numbers representing the values of worlds. (In section V I consider whether the AFS can be defended if it turns out that world-values are not measurable at all.)

The remainder of this paper is structured as follows. In section II I present the three most common arguments for (2) in the literature. (Often these are presented as arguments for the stronger claim that there is no best world.) Defenders of these arguments, I suggest, ought to accept some theological assumptions about how God acts if he exists. But these assumptions imply that if God exists, the world is infinitely valuable.

The defender of (2) might maintain that even if our world is infinitely valuable, it is still improvable. Contra this, in sections III and IV I consider some general principles that philosophers have proposed for how to rank infinitely valuable worlds, and argue that the above three arguments for (2) fail if formulated by means of such principles. In section V I further argue against a "particularist" defense of (2) that denies the need to appeal to general principles for dealing with infinite value. Finally, in section VI, I consider the implications of my argument for atheistic arguments from evil more generally.

\section{Arguments that the World Could be Improved}

One common argument for (2) focuses on the number of value-bearers in the world, usually persons. For example, imagine our world (henceforwardly, '@'), but with one more

Thomson (2008: 19) denies that talk of the goodness of worlds makes sense, on the grounds that "possible world" is not a goodness-fixing kind. I am sympathetic to her criticisms, but I suspect that even if she is right there is some similar concept that can do the same work in the argument. For example, we could talk instead about the desires that God necessarily has (given his perfect nature), suppose that there is some way of balancing these off (some divine decision theory), and claim that, other things equal (e.g., absent deontological side-constraints) a perfect being will maximize desire satisfaction. Then to respond to the AFS I would need to show that God's desires would not be better satisfied in some other world than in this one. 
happy person. This other world (so the argument goes) is better than @. More generally, imagine some world $\mathrm{W}$. Now imagine $\mathrm{W}^{*}$, which is qualitatively identical to $\mathrm{W}$ except that it contains one more happy person. $\mathrm{W}^{*}$ is better than $\mathrm{W}$. But for any world $\mathrm{W}$, we can imagine a $\mathrm{W}^{*}$ with one more happy person. So for any possible world, there is a better world. ${ }^{7}$

A related argument for (2) focuses on the variety of goods in @. A distinguished tradition in Christian theology views the goodness of the world as depending not (just) on the number of creatures in the world, but also on the variety and diversity of the kinds of creatures in the world. This is sometimes called the principle of plenitude. In the Summa (Ia.47.1), Aquinas writes that:

[God] brought things into existence in order to communicate His goodness to creatures and to represent His goodness through them. And since His goodness cannot be adequately represented by any one creature, He produced many diverse creatures, so that what was lacking in one's representation of the divine goodness might be supplied by another. For the goodness that exists in a simple and uniform way in God exists in a multiple and divided way among creatures. Hence, the universe as a whole participates in and represents God's goodness in a more perfect way than any other creature does. ${ }^{8}$

But consider again $\mathrm{W}$ and $\mathrm{W}^{*}$, and this time make $\mathrm{W}^{*}$ qualitatively identical to $\mathrm{W}$ except that it contains one more species or kind of creature in it. It seems that $\mathrm{W}^{*}$ exhibits more variety than $\mathrm{W}$, and so is (by the above reasoning) better than it. But this is true for any $\mathrm{W}$ and $\mathrm{W}^{*}$, and so for any world there is a better. ${ }^{9}$

A third argument for (2) concerns the quality of creaturely experiences. Instead of suggesting that God could create more creatures, this argument notes that he could have made the experiences of actual creatures different. Here is how Perkins (1983: 242) puts the argument:

Imagine a world $\mathrm{W}^{*}$ which, if actualized, would be just like the actual world @ in all respects except that $\mathrm{W}^{*}$ would contain an event $\left(\mathrm{E}_{\mathrm{k}}{ }_{\mathrm{k}}\right)$ which is slightly less painful than its corresponding event $\left(\mathrm{E}_{\mathrm{k}}\right)$ in @. Let us suppose that $\mathrm{E}_{\mathrm{k}}$ is the momentary twinge of toothache of my neighbor's Irish terrier. What we are saying, then, is that the worlds @ and $\mathrm{W}^{*}$ would be just alike except that in $\mathrm{W}^{*}$ the dog's toothache would be slightly less painful than it is in @.10

If we understand 'suffering' broadly enough to include examples such as Perkins's, then we can take this argument to suggest that God could have bettered our world by making creatures suffer less. As this formulation suggests, this argument is the most similar to better-known arguments from evil, such as Rowe's (1996) argument that the existence of God is incompatible with the existence of gratuitous (unnecessary) suffering. I discuss these similarities more in the final section of this paper.

We have seen three propositions which defenders of (2) cite in its support:

7

Variations on this argument are given in Plantinga (1976: 61), Reichenbach (1982: 125), Morris (1993: 237), Swinburne (1994: 134-36, 2004: 114-15), Rowe (2004), and Monton (2010: 124-27).

8 Augustine expresses similar ideas in his City of God, Book XI.

9 This argument is made in Reichenbach (1982: 127) and Rowe (2004: 51-52).

10 I have silently altered Perkins's notations to match my own, and corrected a typo ('even ( $\mathrm{E}_{\mathrm{k}}$ )' instead of 'event $\left.\left(\mathrm{E}_{\mathrm{k}}\right)^{\prime}\right)$. 
(4) If God exists, he could have made a better world than this one by creating more creatures.

(5) If God exists, he could have made a better world than this one by creating more species.

(6) If God exists, he could have made a better world than this one by lessening the suffering of creatures.

In evaluating the goodness of the world, we ought to consider the entire world, including both past and future. ${ }^{11}$ When we do this, we have to consider whether or not there is an end to the world at which we can look back and evaluate it on the whole, or whether the world continues going on (and changing) forever. Defenders of (2) often tacitly assume that the world is spatially and temporally finite. However, I will now argue that anyone sympathetic to (4)-(6) should hold that, if God exists, this is not so.

Leibniz (1710: s. 195-96) similarly emphasized the infinitude of the world in denying (2):

Someone will say that it is impossible to produce the best, because there is no perfect creature, and that it is always possible to produce one which would be more perfect. I answer that what can be said of a creature or of a particular substance, which can always be surpassed by another, is not to be applied to the universe, which, since it must extend through all future eternity, is an infinity. ... [T] he adversary will be obliged to maintain that one possible universe may be better than the other, to infinity; but there he would be mistaken, and it is that which he cannot prove.

I follow Leibniz in thinking that the world "extend[s] through all future eternity." However, most contemporary cosmological theories imply that either our particular universe will come to an end or there will come a time at which no more living things can exist in it. Supposing that, as in many traditional forms of theism, the people in the universe all continue to exist in some afterlife after death, will God then simply focus all his attention on the afterlife existence of those people he has already created, or will he create more people (either by altering the conditions of our universe to allow for life, or, more plausibly, by creating a new universe)?

It is plausible that he will create more people. We could motivate this by saying, in line with (4) above, that the world would be better if it contained more people (assuming their lives ultimately go well, at least), and that God would want the world to be better. More generally, whatever considerations led God to create creatures in the first place, those same considerations would plausibly lead him to continue to create. For example, suppose that God has a desire for communion with other persons. There is no reason to think that he would not desire communion with still more persons once he has created 10 billion, or 100 billion, given that there are no limitations on how many persons God

11 Hick (2010: 81; cf. 166) objects to Leibniz's claim that this is the best of all possible worlds on the grounds that "if this world, with its evils, is the best that is possible, there is no scope or hope for improvement." But this wrongly assumes that if the world is unimprovable as a whole then it is unimprovable at a time. 
can be in a relationship with. Or suppose that God's creating finite persons is an expression of his love and creativity. Creating more finite persons does not cease to be an expression of his love and creativity after he has created 10 billion, or 100 billion, and so it seems that God would continue to express his love and creativity by continuing to create. $^{12}$

In what follows I will assume that if God exists, he will continue to create more people as above. I will further assume that people will continue to exist eternally in an afterlife. ${ }^{13}$ Finally, I will assume that, if God exists, universalism is true - in particular, that for any person, there is some time at which that person becomes morally perfect and enjoys full communion with God. These last two assumptions ought to be amenable to anyone who thinks that God could improve the world by lessening the suffering of creatures or by providing them with positive experiences. ${ }^{14}$

I think that these theological assumptions are both plausible and compatible with orthodox Christianity. But for those theists inclined to view them with suspicion, let me reiterate that their role in my argument is primarily dialectical: that is to say, they are motivated by arguments philosophers tend to give for the second premise of the AFS. Theists who reject these theological assumptions are thus likely to reject these arguments, and so reject the AFS on independent grounds. Readers so inclined can view my argument in this paper as showing that even if one grants the atheist the problematic claims made in defenses of the AFS, the argument still fails to show that God does not exist.

If we do accept the above assumptions, the sum total of value in the world is apparently infinite. Each individual person enjoys everlasting communion with God, the highest good possible, and so each individual's life is infinitely good on the whole. Since there are, over the whole of time, an infinite number of persons, there are then an infinite number of infinitely valuable lives in the world.

We should not just suppose that the value of the world is equal to the total value of people's lives. This would amount to assuming that the value of a world is equal to the sum of the values of the value-bearing parts of a world (in a slogan: the value of a world is the value in a world), and that people are the only value-bearing parts of a world. Neither of these assumptions is obvious. However, it is independently plausible that if the world is as I have supposed here, the value of the world is infinite. For example, suppose that the value

12 This idea is thoroughly Leibnizian. Kretzmann (2001: 224) endorses a similar Neoplatonist principle that "Goodness is by its very nature diffusive of itself and (thereby) of being," and notes that Aquinas often appeals to this principle. Swinburne (2004: 117) agrees and suggests, as I do, that this implies that "a good God to whose power there is no limit will inevitably go on making more good things" (a conclusion Aquinas does not endorse); however, Swinburne does not recognize the implications that this has for his claim that there is no best world. Turner (2003: 146-48) uses a similar claim to motivate his "multiverse" theodicy (discussed later in this section).

The astute reader will note that I have been moving back and forth between 'people' and 'creatures.' I am deliberately vague about what kinds of living things are included in God's continual creation and in the afterlife. I am inclined to think that God will continue to create all kinds of conscious beings, and agree with Dougherty (2014) that in the afterlife God will redeem non-human animals as well as humans. My claims about God creating more people and giving everyone infinitely valuable lives should be understood to apply to whichever creatures are redeemed in the divine plan, whether this includes only humans (and similarly intelligent extra-terrestrial species) or non-human animals as well.

14 Many Christian theodicists have endorsed universalism in the course of addressing the problem of evil (e.g., Hick [2010: ch. 16], Adams [1999: 157], Collins [2013: 226-27]). The prospects of offering an adequate explanation of evil may well be dim if we accept the traditional doctrine of an eternal hell (Adams [1993], Buckareff and Plug [2013]). 
of the world is a function of the average value of people's lives. If people's lives all have infinite value, then the average value of lives in the world is infinite. Or suppose that the value of people's lives contributes to the value of the world, but that there are other value facts that also make a difference: e.g., the quality of relationships in the world, the justice of social arrangements, etc. I am unable to think of any plausible candidates that are not, in the eschaton, as good as we could wish them to be-presumably people's relationships are perfected, for example, and there is no unjust inequality. So it seems that for most plausible determinants of the value of the world, the value of the world is infinite.

One might still try to defend (2) even if the world is as just described, on the grounds that infinitely valuable worlds can still be improvable (Rowe [2004: 51]). Swinburne (2004: 115) and Monton (2010: 124-27), for example, both think that God can add to an infinite number of people, and many multiverse theodicists tacitly assume this in their discussions; such philosophers appear to hold that (4) is true even if the world is as described above. Similarly, one might argue that (6) remains true, because even if in the afterlife everyone eventually enjoys the beatific vision, God have lessened people's suffering in their earthly lives. The next three sections are devoted to showing that if the world is as described above, God could not improve the world in these ways: not only is the world infinitely valuable, it is unsurpassable. In section III I argue against (4) and (5); and in sections IV-V I argue against (6).

Before concluding this section, let me comment on the relationship between my position and another response to the AFS that several philosophers have discussed in recent years-so called "multiverse theodicies" (Kraay [2012]). ${ }^{15}$ Typically, these theodicies claim that God has created every universe that is worthy of creation-e.g., every universe that on-balance contains more good than evil. In so doing, they claim, God has created the best possible world - for our world would be worse if any universe were removed from it, and worse if any on-balance bad universe were added to it.

The most natural way for a continual creation to occur is for God to continue creating universes. My position is thus naturally construed as a multiverse theory, and indeed, some of my remarks in later sections attack arguments for (2) made by critics of multiverse theodicies (e.g., Monton 2010). However, my position differs from extant multiverse theodicists' in that I do not think that God creates every creation-worthy universe. It does not make sense to me to make universes, rather than persons, the primary loci of value. While I am open to the claim that other parts of the world besides persons, like relationships, play a part in determining its value, it does not seem plausible that the value of the universes in the world contributes to the total value of the world above and beyond the value of the things in those universes. So the divine policy "find the good universes, and create those," does not seem to me as natural as "find the possible people whose lives are worth living, and create them," "16 or "find the personal relationships worth having, and bring about those," or something more along those lines.

15 Representative examples include McHarry (1978), Forrest (1981), Turner (2003), and Hudson (2013). For criticisms see Perkins (1980), Almeida (2008), and Monton (2010). Kraay (2012) contains further discussion and references.

16 I think all lives are worth living, and so I am inclined to think that if it is possible for God to create all possible people he does so (see section III for some reasons that this may not be possible). But if (contrary to fact, I would argue), there are some people such that, say, God cannot prevent them from being eternally damned, I don't think God creates those people (this would be the analogue of God only creating universes which are good on the whole). 
Admittedly, these policies might come to the same thing. But Almeida (2008: 14950); cf. Kraay (2012: 149-50) gives a plausible reason to think that they will not. Unless some form of Leibnizian essentialism is true, there will be universes which are each individually creation-worthy but which cannot jointly be created, because they contain some of the same objects. For example, if our universe is creation-worthy, there is plausibly a possible universe that is just like this universe except that in it, I eat oatmeal rather than toast for breakfast this morning. Since I would exist in both of these universes were they actual, but I can in fact exist in only one universe, God cannot create them both. Hence, God cannot create all creation-worthy universes.

As far as I can see, no analogous problem affects the claim that God creates all possible people (or all possible people with overall good lives). It does not seem as plausible that one person's existing makes it metaphysically impossible for another person to existthough see the discussion of Leibnizian essentialism in the next section. Of course, there are many different ways in which all possible people can exist, and I am not claiming that any way is as good as any other. But neither do I claim, as most multiverse theodicists appear to, that there is some unique way that is best. Rather, I make the weaker claim that the way in which God actually creates is unsurpassed - there is no better way that he could have created instead, even if there are also other no worse ways that he could have created.

\section{Improving the World by Adding Value-Bearers}

On the simplest theories of how the value in a world determines the value of a world, the latter is in some way a function of some "value-bearing parts" of the world-e.g., persons or moments in time. Following Vallentyne and Kagan (1997: 5), I will call these value-bearing parts 'locations.' The most natural function is additive: the value of a world is equal to the sum of the values at its locations. There are other possibilities, though. Vallentyne and Kagan mention three: taking the average of the values at the locations of a world, taking the minimum of those values, and measuring how equal the distribution of value is across the locations. One could also combine these for a more complicated aggregation function.

With this framework in hand, we can represent a world with $n$ locations as follows:

$$
\mathrm{W}:\left\{r_{1}, r_{2}, r_{n}\right\}
$$

where the $r_{i}$ are real numbers. Assuming that value is additive, the value of $\mathrm{W}$ is equal to the sum of the sequence $r_{1}, r_{2}, \ldots r_{n}$. (Countably) infinite worlds work the same way, except that the sequence is infinitely long. So, for example, the value of

$$
\mathrm{W}_{1}:\{1,1 / 2,1 / 4, \ldots\}
$$

is 2 .

Things get tricky when we encounter worlds like the following:

$$
\mathrm{W}_{2}:\{1,1,1, \ldots\}
$$

Since the value of $\mathrm{W}_{2}$ 's locations are not decreasing in a convergent series as in $\mathrm{W}_{1}, \mathrm{~W}_{2}$ has infinite value. It is an open debate in the literature on infinite utility whether worlds 
like $\mathrm{W}_{2}$ can be improved upon. ${ }^{17}$ If all we are concerned with is the sum of the values of the locations in $\mathrm{W}_{2}$, then $\mathrm{W}_{2}$ cannot be improved upon (setting aside for the moment the possibility of larger cardinalities of infinity). Several philosophers, however, have found it plausible that there are other general principles according to which other worlds could be better than $\mathrm{W}_{2}$. Roughly speaking, these principles hold that we can improve infinitely valuable worlds in the same two ways we improve finitely valuable worlds: by adding more locations with positive value, or by adding more value to the already existing locations.

With regards to the first kind of improvement (adding locations), Monton (2010: 124) suggests the following:

Adding Locations If (i) $\mathrm{W}^{*}$ has all the locations that world $\mathrm{W}$ has and then some, (ii) the values of the shared locations are the same, and (iii) the values of the non-shared locations in $\mathrm{W}^{*}$ sum to a positive number, then $\mathrm{W}^{*}$ is better than $\mathrm{W}^{18}$

With regards to the second kind of improvement (adding value to existing locations), Vallentyne and Kagan (1997: 11) suggest the following:

Improving Locations If (i) $\mathrm{W}^{*}$ and $\mathrm{W}$ have exactly the same locations, and (ii) for any finite set of locations there is a finite expansion such that for all further expansions, $\mathrm{W}^{*}$ is better than $\mathrm{W}$, then $\mathrm{W}^{*}$ is better than W. ${ }^{19}$

In the next section I will consider Improving Locations, and whether it can be used to vindicate (6) in an infinite world. In the remainder of this section I will consider the possibility that Adding Locations can be applied to show that the actual world can be improved by adding either persons or species to it, thus vindicating (4) or (5). I will assume that value is additive for the purposes of this section, because Adding Locations only makes sense if value is additive. For example, if the value of a world is equal to the average or minimum value of its locations, then adding a location to an infinite world with a positive value less than all the presently existing locations ought to make that world worse.

Suppose that persons are the value-bearing parts of the world, and the theological framework I outlined in section II is correct. If persons are locations, there are numerous ways in which the value at a location might be determined. We might look at a person's overall happiness, her overall moral virtue, or her flourishing more broadly conceived. ${ }^{20}$

17 Vallentyne and Kagan (1997) is the best-known defense of the claim that infinitely valuable worlds can be improved. Articles arguing against this claim include Cain (1995) and Hamkins and Montero (2000).

18 I have silently altered Monton's wording, and the label is mine. Compare Vallentyne and Kagan (1997: 20n18).

19 As above, I have slightly altered wording and the label is mine. Vallentyne and Kagan formulate stronger principles than this one, but the complications they introduce are not relevant to our discussion; and they are only applicable if locations are "naturally ordered" like times, a possibility I discuss and dismiss in the next section. Note also that while Monton's principle assumes that value is additive, Vallentyne and Kagan's does not.

20 The value "at" a personal location might differ from what is ordinarily meant by talk of the value of a person. For example, how much value a personal location contributes to the world will plausibly depend on how good of a life that person has. But a person might be valuable in the ordinary sense and have a bad life. 
On any of these conceptions, my theological assumptions imply that each person's life is infinitely good on the whole. We can then represent the actual world as follows:

$$
@_{1}:\{\infty, \infty, \infty, \ldots\}
$$

$@_{1}$ has two notable features. First, its total value is infinite. Second, each location has infinite value. So both the total value of the world and the value of each of the locations in the world are as high as they can be.

Nevertheless, Adding Locations suggests that $\mathrm{W}^{*}$ could be better than $@_{1}$ if it had more people than $@_{1}$, in a certain sense of 'more.' What would it mean for God to create more people than he creates in the actual world? The cardinal numbers measure the number of elements in a set. Finite cardinal numbers are the familiar natural numbers, but greater than all the finite cardinal numbers are the infinite cardinal numbers, $\boldsymbol{\aleph}_{0}$ (pronounced 'aleph-null'), $\boldsymbol{\aleph}_{1}$, and so on. Any infinite set which has countably many members (i.e., it is possible to order those members, and then "count" them in that order) has a cardinality of $\boldsymbol{\aleph}_{0}$. Consider, for example, the set of natural numbers:

$$
\mathbf{N}:\{1,2,3, \ldots\} \text {. }
$$

Now consider the set of even numbers:

$$
\mathbf{E}:\{2,4,6, \ldots\}
$$

Two sets have the same cardinality if their members can be put in a 1-to-1 correspondence with each other. The members of $\mathbf{N}$ and $\mathbf{E}$ are like that: one can get from $\mathbf{N}$ to $\mathbf{E}$ just by doubling each member. Thus, $\mathbf{N}$ and $\mathbf{E}$ have the same cardinality, $\mathbf{\aleph}_{0}$.

For God to create a bigger cardinality of people, he would have to create uncountably many people. Let's set that possibility aside for the moment, and assume that God can only create countably many people. No matter how many he creates, the cardinality of people in the world remains the same. So in this sense, God cannot create more people than he does.

There is, however, another sense in which we might say that $\mathbf{N}$ has more members than $\mathbf{E}$ : $\mathbf{N}$ has all the members that $\mathbf{E}$ has and then some. This is the sense of 'more' that Adding Locations appeals to in suggesting that God creates more locations in $\mathrm{W}^{*}$ than W. On this sense of 'more,' $\mathbf{N}$ has more members than $\mathbf{E}$, but does not have more members than

$$
\mathbf{E}_{0}:\{0,2,4,6, \ldots\}
$$

Let's suppose that Adding Locations is right, and that adding more (valuable) locations in this latter sense makes a world more valuable. And let's further suppose that persons are locations, as (4) would have it. I will now argue that even so, (4) is false, because we cannot meaningfully say that there is some other creatable world $\mathrm{W}^{*}$ that has all the people in@ and then some.

The first reason that we cannot do this is that it is not clear that there is now a determinate fact about the relevant future properties of @-in particular, its future locations. For example, the following seems plausible: if at time $t$ there are multiple actions that 
God has most reason to perform, he will (given his perfect rationality) perform one of them, but he is not determined to perform one of these actions rather than another. It is likewise plausible that God is in this situation for some of his creative acts in @: that at some time $t$ God is free to create either person 9.2 or person 3.17, say. Condition (i) of Adding Locations requires that for some world $\mathrm{W}^{*}$ to be better than @, "W* has all the locations that world@ has and then some." However, if the above is correct, there may be no determinate fact of the matter about which locations @ has. There can thus be no other creatable world $\mathrm{W}^{*}$ such that the set of people in @ is a proper subset of the set of people in $\mathrm{W}^{*}$, because there is no well-defined set of all the people in @.

The above way of putting this point suggests that God acts in time. Indeed, I have in general spoken as if God is in time; I have said, for example, that after the physical death of currently existing creatures, God will continue to create more. However, many classical thinkers have held that God is outside of time. If this is so, then it may initially seem that God could create everything in @ "all at once," as it were, in which case it does arguably make sense to say that there is some other world $\mathrm{W}^{*}$ he could have created instead with all the people in @ and then some.

I am inclined to accept the traditional doctrine of divine atemporality. Accordingly, I plead guilty to speaking loosely about God's actions. However, the above points still stand even if God is outside of time. Defenders of divine timelessness nevertheless tend to think that we can logically order God's actions (Leftow [1991: 145]). An example of a debate about the logical order of God's actions is the intra-Calvinist dispute about whether God's decree to save some humans is logically posterior or logically prior to his decree to permit humans to fall into sin (Plantinga [2004: 1])—where the latter option would preclude God's basing his decision to save some humans on the fact that he allows some to fall into sin. What really matters for us here is whether God's actions are logically ordered, not whether they are temporally ordered. So long as God's creation of (say) universe A is logically prior to his creation of universe B, we can speak of him "continuing to create" in the way I have done in this essay. ${ }^{21}$

On the specific point at issue here, it is not obvious, given that God's actions are logically ordered, that there is a logical end to the infinite series of creative acts we are considering, just as I earlier contended that there was no temporal end to God's creative acts if God is in time. More precisely: if we consider the logically ordered set of all God's actions, in which logically prior acts precede logically posterior acts, it may be that this set has no last member. This implies that if we are able to attribute properties to the set of all God's actions, we must have some well-defined limiting process by which we can "construct" that set. ${ }^{22}$ But now my argument above applies: though God may necessarily act in accordance with some general policy in adding to this set, this policy may not be specific enough to determine his precise actions. Which of several particular acts he performs at a (logical) time may sometimes be indeterminate, so that we cannot say that

21 It is possible that when we logically order all of God's actions, we will find that some actions consist in creating multiple universes - e.g., universes A and B. When multiverse theodicists speak of God creating multiple universes, most seem to have in mind his creating them in a single action in this way (we could also speak of God performing multiple actions in a "divine instant," and this would come to the same thing). It is compatible with my view that God creates multiple universes "all at once" in this manner; but we can still ask, even if God does this, whether he does anything logically after this. 
there is some other world $\mathrm{W}^{*}$ with all of the people in @, because it is indeterminate who all the people in @ are. $^{23}$

This is the first reason to doubt that we can meaningfully say that there is some other creatable world $\mathrm{W}^{*}$ that has all the people in @ and then some. But let us suppose that there is no problematic indeterminacy in the properties of @. The claim that we can meaningfully say that $\mathrm{W}^{*}$ has all the people in @ and then some nevertheless incurs controversial metaphysical commitments.

I presume that there are some facts about a person in a world in virtue of which that person is the person she is. On one extreme, there is the Leibnizian view that all the properties, including relational properties, of a being are essential to that being. On this view all facts about a person make that person the person she is. On the other extreme, a person is the person she is just in virtue of the non-qualitative (and presumably brute) fact that she is (say) person 3 .

The defender of (4) faces a balancing act. On the one hand, he must maintain that nothing too close to Leibnizian essentialism is true. For if too many facts about a person make that person the person she is, then it is impossible for two distinct worlds $\mathrm{W}$ and $\mathrm{W}^{*}$ to contain all the same persons. For example, person 3 in $\mathrm{W}$ may have the property of being the third person created in the world, whereas the person in $\mathrm{W}^{*}$ who is otherwise qualitatively identical to person 3 may have the property of being the fourth person created. In this case all we can say about $\mathrm{W}$ and $\mathrm{W}^{*}$ is that they each contain $\boldsymbol{\aleph}_{0}$ people; neither set of people is a subset of the other, and so neither has more people in either sense of 'more.'

On the other hand, the fewer the facts about a person that make that person the person she is, the more limits there will be on how many possible people there are. For example, suppose that the identity of a person is determined by the qualitative fact that her genetic code is the way it is at the moment she is conceived. Since genetic codes are finite, there are only countably many possible codes. Hence, there are only countably many possible people that God can create. So, (by the definition of countability) it is possible for God to put all possible people in an order. So, it is possible for God to (mentally) order them and then create them in that order. Let's suppose that God does this in @. In this case, it is not possible for God to create one more person than he does in@. For in@ he actualizes all person-possibilities, and so creates all the people he can. Just as you cannot add any more natural numbers to the set $\{1,2,3, \ldots\}$, so you cannot add any more people to @. They're all there already.

So, for Adding Locations to be applicable to @, it needs to be the case that few enough facts determine identity that the same people can exist in both @ and $\mathrm{W}^{*}$. However, the facts that do determine identity need to be such that there are an uncountable number of possible people for God to create.

If there are uncountably many possible people, then the defender of improving the world by adding people may not need to appeal to Adding Locations at all. One might think that an omnipotent being like God can just create a world $\mathrm{W}_{\mathbf{N}}$ with a higher cardinality of people than @ (Monton [2010: 124-27]) - $\boldsymbol{\aleph}_{1}$, say. In this case it does not matter whether the set of people in $@$ is a subset of the people in $\mathrm{W}_{\mathbf{N}}$, so that neither my first objection to the applicability of Adding Locations nor Leibnizian essentialism

23 Depending on how we think of divine freedom in this case and the nature of God's choices, this scenario may imply that God is not able to know his own future free actions (Swinburne [1994: 134]). 
threaten this scenario. Since $\boldsymbol{\aleph}_{1}>\boldsymbol{\aleph}_{0}$, a world with $\boldsymbol{\aleph}_{1}$ valuable locations in it is more valuable than a world with $\boldsymbol{\aleph}_{0}$ valuable locations in it.

If, however, there are uncountably possible people, and it is possible for God to perform uncountably many actions, then it is again not clear that in@ God does not simply create all the possible people there are. For suppose that there is some set of all possible people. Then, if there are no barriers to God's performing any uncountable number of creative acts "in an instant," he should be able to create all the people in that set (for example, a God who can perform uncountably many acts could presumably create an infinite number of objects each with a size of $r$ units for each positive real $r$; so why could he not create a person corresponding to each $r$ ?). And if God does create all possible people in @, then it is not possible for him to create more, in either sense of 'more.'

So the defender of improvability by addition must say that there is no set of all possible people. In particular, he must say that, for every cardinality $\boldsymbol{\aleph}_{n}$, there are more than $\boldsymbol{\aleph}_{n}$ possible people. In this case, I think it is at best unclear whether God can create a world such that it is not possible for him to have created another world with more people. For example, perhaps God can perform so many creative actions in a particular divine instant that there is no set of all the actions God performs in that instant. Perhaps, for example, at some instant (or at each instant) he creates more than $\boldsymbol{\aleph}_{n}$ universes for any cardinal number $\boldsymbol{\aleph}_{n}$. If we consider all of God's actions in this scenario, does he create fewer people than he could have otherwise? It is at least not obvious that the answer to this question is yes. This question involves quantifying over a number of creative actions too large to be measured by any cardinal number, and it is difficult to even understand, much less answer, a question like that.

Similar problems to the above befall (5), the claim that God can improve the world by creating more species - the thought being that the world is improved by having greater variety in it. One way to formalize this is to take species to be locations, and take some facts about species (e.g., the flourishing of particular members of that species) to determine the value of each location. Then we can sum the locations and, in accordance with the principle of plenitude, the more species there are, the greater the overall value of the world will beat least for all finite worlds. When we get to infinite worlds, then if we accept Adding Locations, adding more species will continue to make the world better.

This faces all the problems (4) faces. If God is able to create uncountably many species, then it is not clear why he cannot create all possible species. Conversely, if God can only create countably many species, it still needs to be the case that there are more than countably many possible species, so that God cannot create all possible speciesand this is not obviously the case. Indeed, it is more plausible that there are only countably many possible species than that there are only countably many possible people- because it is more plausible that species are individuated by something like a genetic code than that persons are. Finally, if there is no determinate fact about which future species God will create, then Adding Locations cannot apply at any rate.

My discussion of the plausibility of (4) and (5) in an infinite world has focused on their elaboration in the formal framework I sketched at the beginning of this section, via the principle Adding Locations. It may be that my formalizations of these propositions do not entirely capture the spirit behind the original positions; in particular, my formalization of (5) as taking species to be locations in the technical sense and the value of the world to be the sum of the value at those locations may not be the best way to elaborate the principle of plenitude in a formal theory of value. But these formalizations have served only to focus 
discussion, and my arguments do not turn on the particular formalizations I have employed. My arguments apply to any position which says that God could have made a better world than this one by creating more people or species, whatever broader theory of value these claims are incorporated into. In addition, although persons and species are the only locations I have considered here, for most other plausible locations, Adding Locations will have many or all of the same problems considered above. For example, if we take locations to be personal relationships, then assuming that in the afterlife God will bring every person into a relationship with every other person, God can only create more relationships by creating more persons, leading to all the difficulties discussed above.

To sum up this section: One might think that God can create a better world than @ by creating a world with more locations than@. For this to be the case, God needs to create a world $\mathrm{W}^{*}$ which either has uncountably many locations or has all the locations that @ does, and then some. The first may not be metaphysically possible, but if it is it is of no help to the defender of (2). For if God can create uncountably many locations, he can presumably create all the members of the set of all possible locations. If there is no such set, because there are too many possible locations, it is as best unclear whether it is necessary that in @, God does not create as many locations as he could have.

For God to add to the world in the second way above, by adding locations to @, @ must have determinate locations. But if some of God's creations are free, it is not obvious that@ has determinate locations. Moreover, @ and other worlds God could have created instead need to be such that the same locations can exist in both-contra Leibnizian essentialism. At the same time, there need to be enough possible locations that God cannot simply create them all in@.

It appears, then, that the most plausible way to defend the claim that God can improve the world by addition is to say that (a) locational (e.g., personal) identity conditions are such that God could have created the same locations in some world $\mathrm{W}^{*}$ as in @, (b) there are uncountably many possible locations for God to create (so that God can create some extra people in $\mathrm{W}^{*}$ ), but (c) God cannot perform an uncountably infinite number of tasks (otherwise he could just create all the uncountable locations), and (d) there is a determinate fact about all of God's (logically) future actions. Jointly, these are high metaphysical costs.

\section{Improving the World by Improving its Parts}

In the last section I argued that (4) and (5) are false, even if Adding Locations is true. My argument there was made easier by the fact that the ways in which the critic thinks God could have improved the world are not ones that we have good reason to believe do not obtain. (For example, we cannot know that God does not create all possible people, nor do we have any good evidence that he does not.) Arguing against (6), however, is more difficult, because we can all see that there is suffering in the world that could have been avoided. Nevertheless, in this and the next section I will argue that (6) is also plausibly false. In this section I will consider a defense of (6) via the principle Improving Locations, and in the next I will consider whether (6) can be defended without appeal to a principle like this.

Here is the principle again for reference:

Improving Locations If (i) $\mathrm{W}^{*}$ and $\mathrm{W}$ have exactly the same locations, and (ii) for any finite set of locations there is a finite expansion such that for all further expansions, $\mathrm{W}^{*}$ is better than $\mathrm{W}$, then $\mathrm{W}^{*}$ is better than $\mathrm{W}$. 
Let us assume - contra critics like Hamkins and Montero (2000: 238-40) - that Improving Locations is correct. I will now argue that even so, neither it nor plausible revisions of it show our world to be worse than it could have been.

One of the objections to applying Adding Locations I made in the previous section applies to any attempted application of Improving Locations (and the revisions of the principle I will go on to consider): it assumes that the locations of @ are definite, so that it is possible to identify some other world $\mathrm{W}^{*}$ such that $\mathrm{W}^{*}$ and @ have all the same locations, but some locations are improved in $\mathrm{W}^{*}$. And as we have seen, assuming that God is free in his continual creation of locations, this is plausibly not the case. But for the rest of this section I will waive this concern, and assume that the possible locations that I will consider are definite in the actual world.

If the locations of a world are persons or something else that given my theological assumptions have infinite value over all of time, then the actual world is still representable as:

$$
@_{1}:\{\infty, \infty, \infty, \ldots\} .
$$

The value of the actual world then remains infinite if we adopt any of the aggregative principles mentioned by Vallentyne and Kagan. The average and minimum of the values at its locations are both infinite, and the distribution of value is completely equal. It should also be clear that Improving Locations does not apply to $@_{1}$ if any of Vallentyne and Kagan's proposed aggregation methods are correct. On any of the above non-additive methods of measuring @ $@_{1}$ 's value, $@_{1}$ is maximally valuable even on any finite set of locations, so (ii) cannot be satisfied. And if value is additive, the fact that each location of $@_{1}$ has infinite value means that Improving Locations does not apply to it. The locations of $@_{1}$ cannot be improved.

The proponent of (6), then, must contend that the locations of a world are not persons, but instead something improvable. ${ }^{24}$ One of the simplest improvable locations is times. Suppose that the value of a time is determined by the net balance of happiness at that time. Since the net balance of happiness at many times is not maximal, then individual locations can be improved-for example by lessening creaturely suffering in the way (6) suggests.

Nevertheless, this still does not let us apply Improving Locations to the actual world. The second clause of Improving Locations requires that for finite subsets of the set of all locations, there is a finite expansion of that subset such that for all further expansions, $\mathrm{W}^{*}$ is better than $\mathrm{W}$. Assuming additivity, this means that

$$
\mathrm{W}_{3}: 2,1,1, \ldots
$$

is better than

$$
\mathrm{W}_{4}: 1,1,1, \ldots,
$$

because, e.g., if the first expansion is our starting location, the total value at any further expansion is 1 greater for $\mathrm{W}_{3}$ than for $\mathrm{W}_{4}$. But we have been supposing that for any

In most of what follows I again assume for ease of discussion that value is additive. I think I could reframe all my points in terms of the other aggregation strategies considered above, however. 
person, there is some time at which that person becomes perfect and enjoys full communion with God. However we are determining value at a time (pleasure, flourishing, selfactualization, quality of relationships, etc.), it seems that the temporal locations after which this occurs will have infinite value, so that the world will look something like this,

$$
@_{2}:\{1,0,-1, \ldots, \infty, \infty, \infty, \ldots\},
$$

where the infinities begin whenever the first person enters the beatific vision. But as far as Improving Locations is concerned, $@_{2}$ is not bettered by

$$
\mathrm{W}_{5}: 2,0,-1, \ldots, \infty, \infty, \infty, \ldots,
$$

because for any starting subset of $@_{2} / \mathrm{W}_{5}$ 's locations, there is an expansion such that the value in both worlds is infinite-e.g., the expansion that first includes one of the locations with infinite value. Since $\infty \ngtr \infty$, Improving Locations does not imply that $\mathrm{W}_{5}$ is better than $@_{2}$.

Perkins (1983: 242-43) seems to suggest taking individual events as locations. This would give us a world more like

$$
\begin{gathered}
@ 3:\{-1,0,2, \ldots, \\
-3,1, \infty, \ldots, \\
4, \infty, \infty, \ldots, \\
\quad \ldots\}
\end{gathered}
$$

where the different lines represent events at different times, and the infinities represent the event of someone enjoying the beatific vision at that time. We could also take creaturely experiences to be locations, giving us a world like

$$
\begin{aligned}
@ 4 & :\{1,0,-1, \ldots, \infty, \infty, \infty, \ldots, \\
& -4,2,5, \ldots, \infty, \infty, \infty, \ldots, \\
& 2,3,-5,-1, \ldots, \infty, \infty, \infty, \ldots, \\
& \ldots\}
\end{aligned}
$$

where the different lines represent different people's lives. But $@_{3}$ and $@_{4}$ still contain (infinitely many!) locations with infinite value, and so Improving Locations still does not apply. Similar remarks apply for other candidate locations, like individual experiences in people's lives.

The defender of (6) has at least two options available to her at this point. She could deny that infinite value at a time is metaphysically possible, and insist that instead the most that God could do is to ensure that people become progressively closer and closer to God, so that the value in a person's life increases without bound as time goes on. This would allow her to keep the value at any given time finite, so that Improving Locations can apply, while retaining the spirit of my universalist assumption (which would still imply that the total value in the world - and in a person's life - is infinite). Call this position quasi-universalism. 
The defender of (6) could also revise (ii) of Improving Locations to say that for all further expansions with finite value, $\mathrm{W}^{*}$ is better than $\mathrm{W}$. Let's call this revision Improving Locations*. So, the proponent of (6) can either embrace quasi-universalism, or embrace Improving Locations*.

Nevertheless, on either of these maneuvers the locations of the world need to be something that sometimes (on Improving Locations*) or always (on quasi-universalism) has finite value. This means that persons still cannot be locations. But the most obvious candidates for improvable locations, times, are intuitively ill suited to play that role. Consider again

$$
\mathrm{W}_{2}: 1,1,1, \ldots,
$$

but now taking the locations to be times, and consider also

$$
\mathrm{W}_{6}: 2,2,2, \ldots
$$

Suppose that God creates $\mathrm{W}_{2}$ by creating one person each day, each of whom lives only for that day and enjoys 1 unit of utility. He creates $\mathrm{W}_{6}$ by creating the exact same people as in $\mathrm{W}_{2}$, but creating the second and third person a day earlier than in $\mathrm{W}_{2}$, the fourth and fifth person two days earlier than in $\mathrm{W}_{2}$, the sixth and seventh person three days earlier, and so on (suppose that none of these people interact with each other, so that there is no other discernible difference between $\mathrm{W}_{2}$ and $\mathrm{W}_{6}$ ). Just as Hilbert can achieve double occupancy in the rooms of his Hotel without adding any guests, so God can achieve double value in the days of his world without making anyone better off. I take it to be clear that under this description, $\mathrm{W}_{6}$ is not better than $\mathrm{W}_{2}{ }^{25} \mathrm{~A}$ world is not made better merely in virtue of its citizens being created faster.

What other possible locations are improvable? One natural proposal, in line with (6), is creaturely experiences. Recall that (6) says that the quality of creaturely experiences could have been better than it in fact is: for example, my neighbor's dog's toothache might have been slightly milder. Here we face a problem with individuating experiences. If the dog's toothache in one world is a different experience than her toothache in a different world, then the two worlds do not share the same experiences and so, if locations are experiences, Improving Locations $\left(^{*}\right)$ is silent. And since the total value of the experiences in both worlds is infinite, the world with the less painful toothache is not better on finitely aggregative grounds either (analogous remarks go for Perkins's suggested locations, events).

One way to avoid incomparability is to take experiences to be individuated by the times that they occur in creaturely lives. But I think there are counterexamples like that

25 This case is similar to Bostrom's (2011: 2.2) counterexample to one of Vallentyne and Kagan's stronger principles; cf. Mulgan (2002: 165-67). Cain (1995) also argues that points in space or time cannot be the value-bearing parts of a world. In Cain's first example, you are in an infinite universe with infinitely many persons. You are forced to choose between creating a continually expanding sphere inside of which everyone is happy, and outside of which everyone is unhappy, or a continually expanding sphere inside of which everyone is unhappy, and outside of which everyone is happy. At any moment of time there is infinite utility in the second scenario, and infinite disutility in the first; however, any person in the world enjoys (over all of time) infinite utility in the first scenario, and infinite disutility in the second. Cain argues that you should bring about the first scenario, and that this suggests that persons, and not moments in time, are the proper loci of value in the world. 
above to times in a life being locations as well. Suppose that there is only one conscious being, and that we are comparing his experiences in two worlds. We are left with the result that

$$
\mathrm{W}_{7}:\{1,2,3, \ldots\}
$$

is better than

$$
\mathrm{W}_{8}:\{0,1,2, \ldots\}
$$

even though $\mathrm{W}_{8}$ might differ from $\mathrm{W}_{7}$ only in that our conscious being took a nap before doing whatever it is that gives him ever-increasing utility in $\mathrm{W}_{7}$. This seems to me a wrong result.

It is also pretheoretically plausible that the bearers of value in the world are the kinds of things we take to have intrinsic moral worth-e.g., persons - rather than things like times or moments in a person's life. Times or creaturely experiences could be moved around, and this would plausibly change the value of a world-for example, a (finite) life that goes from bad to good seems better than one that goes from good to bad, even if the total amount of happiness in each life is equivalent. This suggests that something like a person's life is a more proper bearer of value.

Other things in the world besides persons, however, may have the kind of requisite moral significance to be locations. For example, one might think that relationships, or just social arrangements, are locations. Defenses of (2) on the basis of such candidate locations face a dilemma: either the proposed locations will not be improvable, or their transworld identity conditions will be too weak to avoid incomparability. ${ }^{26}$ Take personal relationships. If we hold the relationship between $\mathrm{A}$ and $\mathrm{B}$ to be constituted by all interactions between $\mathrm{A}$ and $\mathrm{B}$, including those in the eschaton, then, given universalism, it is plausible that all relationships will be infinitely good on the whole. If, by contrast, we limit personal relationships to shorter periods of time so as to include imperfect Earthly relationships, we face a problem of not only giving non-arbitrary identity conditions, but of also ensuring that those conditions are such that my (Earthly) relationship with my wife in @ and my relationship with my wife in $\mathrm{W}^{*}$ are the same relationship, but with different properties, rather than different relationships (making@ and $\mathrm{W}^{*}$ incomparable as far as Improving Locations(*) is concerned). Steering between the horns of this dilemma would be a difficult task.

My objections to (6) so far have supposed that either Improving Locations or Improving Locations* is the strongest principle of its type that applies in worlds with infinite value. Vallentyne and Kagan indicate in a footnote (20n18) that they think that Improving Locations "would remain plausible ... if it were revised to apply to worlds where all, except perhaps for a finite number, of infinitely many locations are the same." As it stands this is a promissory note; they do not tell us how to revise Improving Locations in this way. (If (i) is revised to say that $\mathrm{W}^{*}$ and $\mathrm{W}$ differ only on finitely many locations, then (ii) must also be changed so as to allow some kind of "mapping" between the locations of $\mathrm{W}$ and $\mathrm{W}^{*}$.) However, I think that many people will share Vallentyne and Kagan's intuition here, and those who do may find my earlier objections unsatisfactory. A critic of my argument may admit that a world lacking some evil present in ours would value. 
have different locations (e.g., experiences) in parts of the world connected to that evil, but think that provided that the worlds are otherwise the same, the world lacking the evil is better.

Even so, it is plausible that these worlds will not be the same apart from that evil, but will differ in infinitely many locations. In an infinite world the possible effects of changing a particular event are greatly increased. An infinite world increases both the number of ways in which a seemingly isolated event can have ramifications elsewhere in the world, and the amount of time free creatures have to respond to evils in the ways appealed to by various theodicies. ${ }^{27}$

For example, suppose that God is working to bring me into communion with himself in the afterlife. What strategies God will engage in will depend on, among other things, what kinds of evils I have experienced or perpetrated. Plausibly, these evils will affect my moral psychology and so responsiveness to different types of moral and spiritual education. In addition, the evils I have experienced or perpetrated may each require particular attention - in order to be purged, atoned for, or made right — before God can become reconciled with me. These responses to the evils in question will have further repercussions for the overall shape of my life, through their influence on my memory, selfconception, and subsequent moral and spiritual development. My overall life may thus differ depending on whether or not I experience or perpetrate a particular evil. Whatever locations end up being, it is then plausible that an infinite number of locations will differ between the worlds in which this evil does and does not occur.

Similar remarks go for our relationships with other persons. Suppose that in the afterlife all finite persons eventually become reconciled with each other. ${ }^{28}$ The process by which this takes place will presumably depend on the actions of the persons involved. The evils that I have committed or suffered in my earthly relationship with my father will necessitate different strategies by which we or God perfect our heavenly relationship. For similar reasons to those given above, the worlds with and without some particular evil in our relationship may thus differ in infinitely many locations.

One might worry that at least some evils will only have negative future effects, so that the above lives or relationships, and so world on a whole, will be worse off for the presence of those evils. This judgment would require a different ranking principle than the hypothetical principle currently under consideration, which requires that only a finite number of locations between the two worlds differ. But let us suppose that there is another ranking principle that vindicates the intuition that an evil that has infinitely many negative future effects, and no positive effects, makes the world worse off.

Even so, it is debatable whether there are evils which will have solely negative effects, as this objection supposes. Consider two recent theodicies, those of Marilyn Adams (1999) and Robin Collins (2013). Adams (1999) holds that the character of the good relationship a person enjoys with God in heaven depends on (among other things, presumably) the evils that person has suffered. She argues that Christ identifies with horror participants through his death on the cross, and that participation in horrors thus allows for a special kind of

\footnotetext{
27 Whether this response will work for animal suffering depends on whether animals continue to exist in an afterlife as well (see note 13). Perhaps the defender of (6) could press animal suffering against those who deny this, but I would simply take this as an argument for including animals in God's ultimate redemptive plan.

28 This makes more sense if there are only countably many, and not uncountably many, people.
} 
intimacy with God. People who have not experienced horrors are also able to enjoy intimacy with God, but the character of their relationship is different. Although Adams does not explicitly say this, it appears that on her view the relationships which different people ultimately enjoy with God are all or mostly incomparable - the horror-participant and the non-horror-participant each enjoy a special relationship with God organically connected to their own life histories, but since the latter is not better than the former the horrorparticipant would not wish away the horrors he has participated in (167).

Adams's theodicy thus challenges the claim that some evils will have uniformly negative effects for our relationship with God. Collins's theodicy, on the other hand, challenges the claim that some evils will have uniformly negative effects for our relationship with other human beings. The central idea of Collins's (2013: 222) "connection-building theodicy" is that certain virtuous responses to evil—such as forgiveness and sacrificial aid-contribute to "ongoing, intrinsically valuable connections ... between personal agents." Collins contends that the ongoing character of these connections makes plausible that they "will eventually outweigh the disvalue of the evils that God must allow in order for them to exist" (222). For my purposes in this paper, however, it is sufficient that these connections contribute positively to our relationships with others in such a way that the world containing a particular evil is not overall worse than the world lacking that evil.

As the above caveat hopefully makes clear, my response to the argument that the world would be better off if not for the presence of evils with uniformly negative effects has not been to defend a "greater-good" theodicy. My point is not that had God prevented some evil, this would have made things worse overall by preventing some greater good or causing some greater evil. Rather, I think that God's preventing any evil plausibly has further effects, good and bad and neutral, throughout the world, rendering the world in which the evil was prevented incomparable with the world in which the evil was not prevented, on any principle like Improving Locations that we could formulate. The above discussion suggests some ways in which this can occur, but it is not meant to be exhaustive.

In this section I have argued that given the theological assumptions with which I started, Improving Locations does not apply to our world, because it has locations with infinite value no matter what we take locations to be. The proponent of (6) could respond by embracing a stronger principle like Improving Locations* or denying that universalism is true if God exists and insisting that instead quasi-universalism is. But the proponent of (6) is still not in a position to show that the world can be improved. For (6) requires that some of the locations of the world be improvable. But examples make clear that eligible locations, like times, are not the loci of value in the world. I have argued that more plausible locations, like persons, have infinite value at them, and so cannot be improved.

Even if, contrary to this, we can identify improvable locations, in an infinite world it is plausible that changing one part of the world will lead to infinitely many other parts of the world being changed as well in a way that makes comparison impossible. For example, preventing an evil a person has participated in may lead to God acting differently to fulfill his goal of redeeming that person or to the character of that person's ultimate relationship with God and others being different. The world in which the evil is prevented and that in which it is not will then plausibly be incomparable even on some hypothetical principle stronger than Improving Locations or Improving Locations*. Finally, this is all assuming that there is a determinate fact about God's future actions and thus the locations of the world, a disputable assumption itself. 


\section{The Particularist Challenge}

In the last two sections I have considered ways in which the proponent of the AFS might defend the claim that God could have made a better world than this one even on the hypothesis that the world is infinite, by appeal to general principles like Adding Locations and Improving Locations. I noted in section III that my objections to (4) and (5) did not rely on their specific formulations within the formal framework I sketched there. However, this is not so obviously true for (6). I suspect that many people will maintain that

(6) God could have made a better world than this one by lessening the suffering of creatures,

but deny that (6) can or needs to be formulated in terms of an infinitely aggregative value theory like Vallentyne and Kagan's. Readers fitting this description may view my appeals to various facts about infinity in criticizing (6) as mere metaphysical parlor tricks. Such readers may simply think it obvious, in light of the horrendous evils in the world, that

(2) If God exists, he could have created a better world than this one,

even given that this world's citizens and their relationships are perfected or continually improved in an afterlife. ${ }^{29}$

I think that my discussion in the last part of section IV casts doubt on the correctness of this intuition even if one does not think it needs to be cast in terms of some particular formal value theory. It is plausible, whatever one thinks about Improving Locations and similar principles, that infinitely valuable worlds that differ in infinitely many ways or in which the infinitely valuable experiences that people enjoy are of a different character are not comparable. Nevertheless, I will also try to respond to this "particularist challenge" more directly.

I do not want to commit myself to the correctness of aggregative value theory, or to any particular formal system for measuring value, or even to the claim that the goodness of worlds can be measured, rather than just partially ordered. For my part, I suspect that value cannot be atomized, and that how a particular part contributes to the good of the whole depends on what the rest of the whole is, just as how a particular part of a symphony contributes to its quality as a whole depends on what the rest of the symphony is. But most arguments for (2), and for (6) more specifically, at least tacitly presuppose some kind of aggregative value theory, usually an additive one. For example, Perkins's (1983) argument for (6) relies on constructing a world W* exactly like @ except that it contains one event which involves less pain. The only way that this can guarantee that $\mathrm{W}^{*}$ will be better than @ is if pain is disvaluable and the value of the world as a whole is increased by any local increase in value. So the main reason that I have framed my arguments in terms of aggregative value theory is because such theories tend to be presupposed by arguments that God could have made a better world than our own.

That said, it is certainly open to a defender of (6) to reject additive or aggregative theories of value. If she does, she can take one of two positions. The first position is that although value is not aggregative, there are still general principles for determining how

29 As Hudson (2013: 241) puts it, "When we focus upon some known and horrid feature of our history, ... it just seems obvious to many that ... the presence of that horrific evil disqualifies our world from being best" - or, we can add, unsurpassable. 
good a world is (these principles may only allow us to partially order worlds in terms of goodness, and not to assign numerical values or ranges to their goodness). The second position is a more radical particularism that says that the only way to judge the goodness of worlds is to look at individual cases.

If the world is infinitely extended into the future, then the second position makes (2) inscrutable. It is impossible for us to know or comprehend all the axiologically relevant facts about an infinite world. We cannot see how the world-part with which we are acquainted fits into the whole well enough to judge whether or not our world could be improved. So if (2) is to be defended, there must be some principle which we can appeal to that says that no matter what the future may bring, the world would be better if it were this other way instead. ${ }^{30}$

However, if the defender of the AFS wishes to argue for (2) on its basis, she must tell us some story about what those general principles are, and we must be persuaded that they do not fall prey to analogues of worries I canvassed above for arguments based on aggregative value theory. I am skeptical that this project can succeed. For what we find in general when introducing infinity into a domain is that arguments and principles that straightforwardly apply in finite cases lead to contradictions or paradoxes when applied in infinite cases - for example, the conclusions that "if a chord in a circle is drawn at random, ... the probability that it will be less than the side of the inscribed equilateral triangle" is $1 / 2,2 / 3$, and $3 / 4$ (Bertrand's paradox, as summarized by Keynes [1921: IV.7]), that one cannot move from point 1 to point 0 because to do so one must first go through points $1 / 2,1 / 4$, etc. (Zeno's dichotomy paradox), and that it is possible to decompose a solid ball and reassemble it into two balls each the same size as the original (the Banach-Tarski paradox). I am not at all confident that in the kinds of scenarios we've been considering, infinite worlds, infinite actions, or infinite value all work in precisely the way I've suggested. But I do hope to have shown that we should be extremely cautious in concluding that arguments about improvability that apply in finite worlds go through in infinite worlds. $^{31}$

30 Dustin Crummett has suggested to me that there may be a middle ground between these two positions: roughly, a view which denied that there are general principles that allow us to even partially order the goodness of the worlds, but which nevertheless held that there are defeasible, pro tanto rules for judging whether a certain feature of the world makes it better or worse. For example, this view might say that an experience being painful tends to make the world in which it takes place worse, absent some special reason to think it doesn't in this case. I suspect, however, that this view will ultimately falter on one of the horns of my dilemma. The more easily overridden these pro tanto rules are, the less plausible it will be that they can tell us that various features of the world in fact make the world worse off than it could have been, given that we are only acquainted with a finite part of an infinite world. The less easily overridden they are, the more they will look like general rules of the kind I suggest we should be wary of when moving from finite to infinite domains.

31 I suspect that the best way for the defender of (2) to meet this challenge is to deny that talk of infinite value makes sense at all, and to adopt a radically different approach to axiology, such as Thomson's (2008) "exemplar" model, on which there is a paradigm case of a good K against which all other Ks are measured. This is one way of reading Fales (2013: 357-62). Fales claims that there is a best possible world, one that contains "nothing but the best." This is a world populated solely by God and creatures that are duplicates of God except that they are caused to exist-they are not a se. Space precludes me from giving this position the attention it deserves. Suffice to say that I think that even if it can be elaborated in a way that avoids the problems with infinity I have raised in this paper, Fales's position is inconsistent with value judgments many theists will be inclined to make. For example, the principle of plenitude discussed earlier sees God's goodness better expressed in a diversity of creatures than in one kind alone. And Hick (2010: 255-56) suggests that it is better, other things equal, for us to start out imperfect and gradually become more perfect than to be created perfect to begin with, especially if the former happens as a result of our own free choices. 
In sum: Proponents of the AFS may wish to argue for (2) "directly," without recourse to principles like Adding Locations or Improving Locations. But the reason these principles were introduced by value theorists in the first place is because evaluative judgments that straightforwardly apply to finite worlds may only apply to infinite worlds under certain conditions. The proponent of the AFS who thus wishes to argue for (2) without appeal to such principles faces the difficult task of showing that her evaluative judgments apply in infinite worlds, despite infinity's notoriously counterintuitive nature. Indeed, if she wishes to eschew moral principles altogether, then it seems that she cannot rationally affirm (2). For if we need to be in possession of all the relevant facts about an object to make a moral judgment about it, then we cannot judge that there is a better world than this one because we can never be in possession of all the relevant facts about this world.

\section{Problems of Evil}

In this paper I have argued against the Argument from Surpassability by denying the premise that God could have created a better world than this one. I have argued that God cannot improve the world by adding value-bearers to it, nor can he improve it by reducing suffering - either because these actions are not possible or because they would not improve the world, but merely replace it with another incomparable infinitely valuable world.

I do not think that my argument defeats the problem of evil broadly conceived. The story I have sketched here leaves mysterious why God brings about or allows the evils we find in the world. For instance, I have not claimed that God uses evil as a means to obtain an infinitely valuable world, or that he could not have created such a world without evil. As such, some arguments from evil are untouched by the arguments in this paper. For example, my criticism of the AFS does nothing to answer Fales's (2013: 35355) contention that a morally perfect God would not allow someone to undergo terrible evils without her consent, even if those evils ultimately contribute to the good of the world or even her own life.

That said, I suspect that the problems that I have identified for the AFS in an infinite world will affect other "consequentialist" arguments from evil. I am thinking in particular of the Argument from Gratuitous Evils, as formulated by William Rowe (1996: 2):

(7) There exist instances of intense suffering which [God] could have prevented without thereby losing some greater good or permitting some evil equally bad or worse.

(8) [God] would prevent the occurrence of any intense suffering [God] could, unless [God] could not do so without thereby losing some greater good or permitting some evil equally bad or worse.

It follows from (7) and (8) that

(3) God does not exist.

(8) is very similar to (1) - i.e., the claim that God would create the best world he can. As stated (8) is not terribly precise, and I suspect that attempts to formalize it in terms of an 
aggregative theory of value would make (8) a special case of (1). (7) would then be very similar to (6) - the claim that God could have made the world as a whole better by making some experiences of creatures better. But I have argued that there are serious difficulties with (6); and (7) would inherit all these difficulties.

This discussion is merely suggestive; responding to the Argument from Gratuitous Evils fully is beyond the scope of this paper. But I would like to close with a suggestion of how my arguments might reorient discussion of the problem of evil. I suspect that just as Bostrom (2011) argues that the problem of infinite utility makes consequentialism an untenable moral theory, the kinds of considerations I have raised in this paper show that God is not a consequentialist - that God's reasons for action are not (only) consequentialist reasons, for the consequentialist goal of maximizing value massively underdetermines what a perfect God would do. In discussing atheistic arguments from evil, both proponents and critics would thus do well to consider the kinds of non-consequentialist motivations a perfect being might have.

\section{Works Cited}

Adams, Marilyn McCord (1993). "The Problem of Hell: A Problem of Evil for Christians," in Reasoned Faith, ed. Eleonore Stump (Ithaca, NY: Cornell University Press), 301-27.

(1999). Horrendous Evils and the Goodness of God (Ithaca, NY: Cornell University Press).

Adams, Robert M. (1972). "Must God Create the Best?" Philosophical Review 81(3): 317-32.

Almeida, Michael J. (2008). The Metaphysics of Perfect Beings (New York: Routledge). Aquinas, Thomas. Summa Theologiae, transl. Alfred J. Freddoso (translation in progress —available at http://www3.nd.edu/ afreddos/summa-translation/TOC.htm).

Blumenfeld, David (1975). "Is the Best Possible World Possible?" Journal of Philosophy 84(2): $163-77$.

Bostrom, Nick (2011). "Infinite Ethics," Analysis and Metaphysics 10: 9-59.

Buckareff, Andrei A. and Allen Plug (2013). "Hell and the Problem of Evil," in The Blackwell Companion to the Problem of Evil, ed. Justin McBrayer and Daniel Howard-Snyder (Oxford: Wiley-Blackwell), 128-43.

Cain, James (1995). “Infinite Utility," Australasian Journal of Philosophy 73(3): 401-4.

Collins, Robin (2013). "The Connection-Building Theodicy," in The Blackwell Companion to the Problem of Evil, 222-35.

Dougherty, Trent (2014). The Problem of Animal Pain: A Theodicy For All Creatures Great And Small (Houndsmills: Palgrave Macmillan).

Fales, Evan (2013). "Theodicy in a Vale of Tears," in The Blackwell Companion to the Problem of Evil, 349-62.

Forrest, Peter (1981). "The Problem of Evil: Two Neglected Defences," Sophia 20(1): 49-54.

Grover, Stephen (1988). "Why Only the Best is Good Enough," Analysis 48(4): 224.

— (2003). "This World, 'Adam's Worlds', and the Best of All Possible Worlds," Religious Studies 39(2): 145-63.

(2004). "Rival Creator Arguments and the Best of All Possible Worlds," Sophia 43 (1): 101-14. 
Hamkins, Joel David and Barbara Montero (2000). "With Infinite Utility, More Needn't Be Better," Australasian Journal of Philosophy 78(2): 231-40.

Hick, John (2010). Evil and the God of Love (Houndsmills: Palgrave Macmillan).

Hudson, Hud (2013). "Best Possible World Theodicy," in The Blackwell Companion to the Problem of Evil, 236-50.

Jaynes, E. T. (2003). Probability Theory: The Logic of Science (Cambridge: Cambridge University Press).

Kant, Immanuel (1978). Lectures on Philosophical Theology, translated by Allen W. Wood and Gertrude M. Clark (Ithaca, NY: Cornell University Press).

Keynes, John Maynard (1921). A Treatise on Probability (London: Macmillan and Co.).

Kraay, Klaas J. (2010). "The Problem of No Best World," in A Companion to Philosophy of Religion: Second Edition, ed. Charles Taliaferro, Paul Draper and Philip L. Quinn (Malden, MA: Wiley-Blackwell).

(2012). "The Theistic Multiverse: Problems and Prospects," Scientific Approaches to the Philosophy of Religion, ed. Yujin Nagasawa (Houndsmills: Palgrave MacMillan), 143-62.

— (2013). “Can God Satisfice?” American Philosophical Quarterly 50(4): 399-410.

Kretzmann, Norman (2001). The Metaphysics of Theism: Aquinas's Natural Theology in Summa Contra Gentiles I (New York: Oxford University Press).

Leftow, Brian (1991). Time and Eternity (Ithaca, NY: Cornell University Press).

Leibniz, Gottfried Wilhelm (1710/1985). Theodicy, transl. E. M. Huggard, ed. Austin Farrar (London: Routledge \& Kegan Paul).

McHarry, John (1978). “A Theodicy,” Analysis 38(3): 132-34.

Monton, Bradley (2010). “Against Multiverse Theodicies," Philo 13(2): 113-35.

Morris, Thomas V. (1993). "Perfection and Creation," in Reasoned Faith, ed. Eleonore Stump (Ithaca, NY: Cornell University Press), 234-47.

Mulgan, Tim (2002). "Transcending the Infinite Utility Debate," Australasian Journal of Philosophy 80(2): 164-77.

Perkins, R. K. (1980). “McHarry's Theodicy: A Reply,” Analysis 40(3): 168-71. (1983). "An Atheistic Argument from the Improvability of the Universe," Noûs 17 (2): 239-50.

Plantinga, Alvin (1976). God, Freedom, and Evil (Grand Rapids: Eerdmans).

- (2004). "Supralapsarianism, or 'O Felix Culpa," in Christian Faith and the Problem of Evil, ed. Peter van Inwagen (Grand Rapids, MI: Wm. B. Eerdmans Publishing Company), 1-25.

Quinn, Philip L. (1992). "God, Moral Perfection, and Possible Worlds,” in The Problem of Evil: Selected Readings, ed. Michael L. Peterson (Notre Dame, IN: University of Notre Dame Press), 289-302.

Reichenbach, Bruce (1982). Evil and a Good God (New York: Fordham University Press).

Rowe, William L. (1996). "The Problem of Evil and Some Varieties of Atheism," in The Evidential Argument from Evil, ed. Daniel Howard-Snyder (Bloomington: Indiana University Press).

- (2004). Can God Be Free? (Oxford: Oxford University Press).

Schlesinger, George (1977). Religion and Scientific Method (Dordrecht: Reidel).

Sobel, Jordan Howard (2004). Logic and Theism: Arguments for and Against Beliefs in God (Cambridge: Cambridge University Press). 
Swinburne, Richard (1994). The Christian God (New York: Oxford University Press). (2004). The Existence of God, Second Edition (Oxford: Oxford University Press).

Thomson, Judith Jarvis (2008). Normativity (Chicago: Open Court).

Turner, Donald T. (2003). "The Many-Universes Solution to the Problem of Evil," in The Existence of God, ed. Richard M. Gale and Alexander R. Pruss (Ashgate: Aldershot), 143-59.

Vallentyne, Peter and Shelly Kagan (1997). "Infinite Value and Finitely Additive Value Theory," Journal of Philosophy 94(1): 5-26.

Wielenberg, Erik J. (2004). "A Morally Unsurpassable God Must Create the Best," Religious Studies 40(1): 43-62. 